\title{
Autism spectrum disorder in adults: diagnosis, management, and health services development
}

\author{
This article was published in the following Dove Press journal: \\ Neuropsychiatric Disease and Treatment \\ 7 July 2016 \\ Number of times this article has been viewed
}

\author{
Clodagh M Murphy ${ }^{1,2}$ \\ C Ellie Wilson ${ }^{1-3}$ \\ Dene M Robertson ${ }^{1,2}$ \\ Christine Ecker ${ }^{1,4}$ \\ Eileen M Daly ${ }^{1,2}$ \\ Neil Hammond ${ }^{1,2}$ \\ Anastasios Galanopoulos ${ }^{1,2}$ \\ Iulia Dud ${ }^{1,2}$ \\ Declan G Murphy',2 \\ Grainne M McAlonan ${ }^{1,2}$
}

'Sackler Institute for Translational Neurodevelopment, Department of Forensic and Neurodevelopmental Sciences, King's College London, Institute of Psychiatry, Psychology \& Neuroscience, ${ }^{2}$ Behavioural and Developmental Psychiatry Clinical Academic Group, Behavioural Genetics Clinic, National Adult Autism Service, South London and Maudsley Foundation NHS Trust, London, UK; ${ }^{3}$ Individual Differences, Language and Cognition Lab, Department of Developmental and Educational Psychology, University of Seville, Spain; ${ }^{4}$ Department of Child and Adolescent Psychiatry, Psychosomatics and Psychotherapy, University Hospital, Goethe-University, Frankfurt am Main, Germany

Correspondence: Clodagh M Murphy Department of Forensic and Neurodevelopmental Science, Institute of Psychiatry, Psychology \& Neuroscience, King's College London, De Crespigny Park, London SE5 8AF, UK

Tel +44 2078480984

Fax +44 2078480650

Email clodagh.m.murphy@kcl.ac.uk

\begin{abstract}
Autism spectrum disorder (ASD) is a common neurodevelopmental disorder characterized by pervasive difficulties since early childhood across reciprocal social communication and restricted, repetitive interests and behaviors. Although early ASD research focused primarily on children, there is increasing recognition that ASD is a lifelong neurodevelopmental disorder. However, although health and education services for children with ASD are relatively well established, service provision for adults with ASD is in its infancy. There is a lack of health services research for adults with ASD, including identification of comorbid health difficulties, rigorous treatment trials (pharmacological and psychological), development of new pharmacotherapies, investigation of transition and aging across the lifespan, and consideration of sex differences and the views of people with ASD. This article reviews available evidence regarding the etiology, legislation, diagnosis, management, and service provision for adults with ASD and considers what is needed to support adults with ASD as they age. We conclude that health services research for adults with ASD is urgently warranted. In particular, research is required to better understand the needs of adults with ASD, including health, aging, service development, transition, treatment options across the lifespan, sex, and the views of people with ASD. Additionally, the outcomes of recent international legislative efforts to raise awareness of ASD and service provision for adults with ASD are to be determined. Future research is required to identify high-quality, evidence-based, and cost-effective models of care. Furthermore, future health services research is also required at the beginning and end of adulthood, including improved transition from youth to adult health care and increased understanding of aging and health in older adults with ASD.
\end{abstract}

Keywords: autism, adults, diagnosis, management, service development

\section{Introduction}

Autism spectrum disorder (ASD) is a neurodevelopmental disorder characterized by pervasive difficulties since early childhood across reciprocal social communication and restricted, repetitive interests and behaviors. ${ }^{1,2}$ Although early research in ASD focused primarily on children, there is increasing recognition that ASD is a lifelong neurodevelopmental disorder that has a potentially detrimental impact on adult functioning. ${ }^{3}$

While health and education services for children with ASD are relatively well established, service provision for adults with ASD is in its infancy. There is a lack of health services research for adults with $\mathrm{ASD},{ }^{48}$ including identification of comorbid health difficulties, rigorous treatment trials (pharmacological and psychological), development of new pharmacotherapies, ${ }^{9}$ transition and aging across the lifespan, ${ }^{10}$ sex differences, life skills, consideration of the views of people with $\mathrm{ASD},{ }^{7}$ and cost and efficiency of services. ${ }^{8}$ Here, we review recent developments in understanding the etiology, legislation, diagnosis, management, and service provision for people with ASD across the adult lifespan and consider what is needed to support adults with ASD as they age. 


\section{Etiology}

\section{ASD - a public health concern}

ASD was initially described as a rare disorder of childhood. ${ }^{11,12}$ However, the estimated prevalence rate of ASD has changed significantly over the past 40 years, perhaps in part because of increasing awareness of ASD and changes in diagnostic criteria and classification systems. ${ }^{13}$ In 1966, the prevalence of autism was estimated to be just four cases per 10,000 people. ${ }^{14}$ However, ASD is now recognized as a common, lifelong ${ }^{15}$ neurodevelopmental disorder that affects $\sim 1 \%$ of both the child ${ }^{16}$ and adult ${ }^{17}$ population.

The estimated prevalence of ASD is increasing, making it more common than several other better recognized conditions, such as heart disease and diabetes. ${ }^{9}$ Despite this, $80 \%$ of adults with ASD report marked difficulties in accessing diagnostic services. ${ }^{18}$ Furthermore, ASD is associated with significant financial and emotional costs to the individual, their families, and society across health, education, and social systems. ${ }^{19}$ The estimated lifetime cost of supporting a person with ASD is substantial: \$2.4 million in the USA and $£ 1.5$ million in the UK. ${ }^{19}$ These costs include accommodation, individual productivity loss (employment/education), and health, all of which may be contributed to by unmanaged mental health difficulties in adulthood. Additionally, preliminary evidence suggests that unmet needs arising from comorbid mental health problems in young adults with ASD contribute to caregiver burden. ${ }^{20}$

The unmet health needs of people with ASD, lack of adult services, ${ }^{6}$ lack of treatment, ${ }^{21}$ and increasing prevalence rate $^{13}$ contribute to the escalating disease burden on people with ASD as they age, their families, and society. ${ }^{9}$ Hence, there is an urgent need for improved mental health care for people with ASD across the lifespan that facilitates rapid, direct translation of scientific findings to clinical care. ${ }^{9,22}$ This should include better understanding of the neurobiological causes of ASD and associated comorbid and cognitive difficulties for children and adults with ASD, development of clinical treatment trials, the provision of high-quality, evidence-based, and age-appropriate treatments, ${ }^{10}$ and consideration of the views of people with ASD in research and services development. ${ }^{7}$

Despite media concerns about an epidemic of autism, ${ }^{23}$ the trend of increased prevalence rates is not thought to relate to an increased incidence of ASD. Instead, there is good evidence that increased prevalence rates of ASD are associated with increased awareness of ASD, a resultant relative increase in service availability, and changes in diagnostic criteria. ${ }^{24-26}$ Accordingly, autism, and the associated spiraling increase in demand for clinical service provision for people with ASD, has been identified by the United Nations and the World Health Organization as a public health concern..$^{27,28}$

Despite this, to date there are no validated treatments for the core symptoms of ASD, ${ }^{29,30}$ and only a limited range of evidence-based treatments exist for associated mental health problems ${ }^{21,31}$ of adults with ASD. As such, there is an urgent need for improved understanding of the neurobiology and health of people with ASD across the lifespan, for consideration of the views of people with ASD and their families regarding service development and research, ${ }^{32}$ and for the development of targeted, individualized, age-specific treatments. ${ }^{9}$

\section{ASD - etiology of a highly heritable neurodevelopmental disorder}

Asperger ${ }^{11}$ and Kanner's ${ }^{12}$ seminal descriptions of children with autism and their families also detailed parental behaviors, and thus provided the first descriptions of possible familial and genetic traits of ASD. However, despite early evidence of a possible genetic contribution to ASD, this was not further investigated for some decades. Instead, psychodynamic theories became influential in the 1960s, and it was suggested that poor parenting and social deprivation caused autism, as evidenced by the damning but previously widely used term refrigerator mothers. ${ }^{33}$

This psychodynamic view of autism was challenged by increasing evidence of genetic associations with autism. For example, Folstein and Rutter' ${ }^{34}$ groundbreaking twin study found not only greater evidence for autism in monozygotic than dizygotic twins but also that identical twins with autism did not have identical symptoms of autism. This provided crucial first evidence of what is now recognized as a determining feature of ASD: heterogeneity.

Genetic investigation of autism started to proliferate in the 1980s with the recognition of the association of rare syndromes and chromosomal disorders with ASD. ${ }^{35}$ ASD is now considered to be a highly heritable, heterogeneous, neurodevelopmental disorder, with an estimated heritability of $\sim 90 \% .{ }^{36}$ However, both genetic and environmental factors are thought to contribute to the development of ASD. A recent twin study ${ }^{37}$ estimated that genetic variables contribute $35 \%-40 \%$ toward the risk of developing an ASD and that the remaining $60 \%$ is contributed to by prenatal, perinatal, and postnatal environmental factors.

Environmental risk factors associated with ASD include prenatal and perinatal complications, ${ }^{38,39}$ exposure to viruses (particularly rubella), birth and neonatal complications, ${ }^{40,41}$ 
such as hypoxia, ${ }^{42}$ and increased paternal age. Studies in Israel and Sweden have reported that children fathered by men older than 40-50 years are two to five times more likely to develop ASD than children fathered by men 29 years or younger. ${ }^{43,44}$ It has been suggested that the increased risk of ASD with older fathers may be related to epigenetic changes associated with aging, including germ-line changes and exposure to toxins. ${ }^{43}$

The risk of developing autism can now be calculated for family members; siblings of people with idiopathic autism have a $2 \%-8 \%$ increased risk of having autism themselves, ${ }^{45}$ (a 25 -fold increase above the general population) ${ }^{46}$ while siblings of people with ASD and a dominant single gene disorder (such as tuberous sclerosis) have a recurrence risk of $50 \% .{ }^{47}$ The genetics of autism are complex, partly due to its significant heterogeneity. Overall, however, there is now overwhelming evidence that ASD is a complex, neurobiologically determined, heterogeneous neurodevelopmental disorder. ${ }^{37,46,47}$

\section{Sex differences}

ASD is diagnosed more commonly in males than females, with a 4:1 male:female ratio. ${ }^{24,48}$ However, the sex vulnerability to ASD appears to change with functioning level; the ratio of males to females in children with both ASD and a learning disability (LD) is $2: 1$, but it increases to 6-8:1 in ASD children who do not have a LD. ${ }^{48}$ This may itself contribute toward an ascertainment bias. For example, a diagnosis of ASD may be more frequently considered in LD females than in non-LD females. ${ }^{49}$ Furthermore, sex differences in symptom presentation (fewer restricted/repetitive behaviors in females) may contribute to differential identification of ASD across sexes. ${ }^{49}$ There is preliminary evidence of abnormalities ${ }^{50}$ and sex-specific differences in the brain structure of females with ASD. ${ }^{51,52}$ Further, there is first evidence of possible sex-differences in degree of genetic anomaly associated with $\mathrm{ASD} .{ }^{53}$ Overall, there is increasing awareness of the need to better understand females with $\mathrm{ASD}^{54}$ and how their neurobiology, symptoms, and clinical detection may differ from those of males. ${ }^{54,55}$

\section{Autism legislation}

Although the importance of providing mental health care for adults with ASD is increasingly recognized, to date there is relatively little evidence-based research regarding health services for adults with ASD and clinical services for adults with ASD are markedly limited. ${ }^{5,6}$ However, government legislation has been introduced internationally to raise awareness of autism and fund research. For example, in the USA, the Combating Autism Act of 2006/2011 and the subsequent Autism Collaboration, Accountability, Research, Education, and Support Act of 2014 aim to provide federal funding of $\$ 3$ billion for autism research, services, and training by 2019. In Australia, funds of $\$ 190$ million were released with the Helping Children with Autism Package of 2008.

In the UK, legislation was introduced to increase awareness of - and mandate services specifically for - adults with ASD. The outcome of this legislation is yet to be determined. However, the UK legislation is reviewed here to illustrate the cross-services working and long-term planning encountered in efforts to raise awareness and develop ASD services. Future comparison of different international approaches to raising awareness of ASD, service development, and measurement of outcomes may contribute to the development of evidence-based care for people with ASD. For example, the 2009 Autism Act (the first ever disabilityspecific legislation in England) included two important and time-specific requirements: that the government produce 1) an adult ASD strategy by April 2010 and 2) statutory guidance (ie, guidance that councils and local health commissioning groups are legally required to follow) regarding implementation of the strategy by December 2010 .

The resulting 2010 UK Adult Autism Strategy provided local authorities and national health organizations with minimum requirements regarding how to provide for the needs of adults with ASD locally. These included provision of autism awareness training for all staff in their employment and also specialist autism training for key staff, such as family doctors and community workers.

However, considerable geographic variation in service provision remained, along with an overall paucity of adult ASD services in the UK. As such, the Autism Strategy was superseded in 2014 by an updated government strategy, Think Autism. ${ }^{56}$ Think Autism required all 2010 strategy recommendations to be upheld and specifically highlighted the legal requirement for 1) improved training of frontline staff in ASD, 2) development of local ASD teams, 3) better planning and commissioning of services with the input of people with ASD and their parents/carers, 4) improved access to diagnosis and postdiagnostic support, and 5) leadership at national, regional, and local levels to help deliver the statutory guidance and determine progress.

The requirements of the Autism Act included service development across health and social services. In the UK, family doctors (general practitioners [GPs]) are the gatekeepers of access to care for patients. As such, it is important that GPs have an awareness of ASD and know how to access 
clinical and social care for their patients with ASD. In order to facilitate this, the UK governing body for family doctors (the Royal College of General Practitioners [RCGP]) designated autism a clinical priority in 2014 and appointed an Autism Champion to provide clinical leadership and deliver innovative clinical programs.

The outcomes of the RCGP autism initiative are not yet available. However, the RCGP plans that it will enable GPs to access high-quality training that will lead to delivery of the best possible community services, including 1) development of ASD friendly services with appropriate referral, 2) timely diagnosis, 3) appropriate support for people with ASD (and their families), and 4) improved health and wellbeing outcomes.

Furthermore, adult community mental health teams and regional councils are setting up local adult autism services to be compliant with Think Autism. Efforts are being made to raise awareness among allied professionals of the needs of adults with ASD and their families, including social workers. ${ }^{57}$ Hence, while much remains to be done, community health and social resources for adults with ASD are evolving in the UK. Although it is too soon to determine the impact of Think Autism, it is hoped that joint working across local primary care, community mental health teams, hospitals, and local authorities will enable greater awareness of ASD and timely provision of high-quality evidence-based local services for all adults with ASD. However, there is an urgent need for research to determine the impact of ASD legislation on people with ASD and their families. ${ }^{7}$

\section{Diagnosis}

\section{Why is clarity of diagnosis important in ASD?}

Although ASD is a common neurodevelopmental disorder, at the moment clear biomarkers are not yet available, and so ASD is defined and diagnosed on the basis of behavior. ${ }^{58,59}$ The diagnosis of ASD has been revised over the last 35 years, and early brain imaging as well as genetic and behavioral investigations of ASD have contributed to significant advances in our understanding of ASD. However, the results of some early studies were contrasting, which may have been contributed to, in part, by the inclusion of people with unclear diagnoses of ASD. ${ }^{59,60}$

Hence, standardized assessment measures of ASD were developed that enabled behavioral observations of the individual and collection of collateral developmental history from a parent or carer to be quantified and used in addition to diagnostic classification systems. ${ }^{59}$ As ASD is diagnosed behaviorally at present, clarity of assessment and diagnosis is important to better understand associations between brain, behavior, and health in people with ASD across the lifespan and enable inclusion of accurately categorized participants in large multisite studies. ${ }^{59,61}$ Better understanding of brain, behavior, and diagnosis in people with ASD will, in turn, lead to future development of age-appropriate and targeted treatments ${ }^{58}$ and thus improved services for people with ASD. As such, the next section will review changes in diagnostic practice in ASD.

\section{Diagnosis of ASD}

Both an increased awareness of ASD and changes to diagnostic classifications may have partly contributed to the increased prevalence of ASD. ${ }^{62}$ Autistic disturbances of affective contact $^{12}$ and autistic psychopathy ${ }^{63}$ were first described in the 1940s and later translated from German to English by Frith. ${ }^{64}$ However, autism was not included as a diagnostic category until the publication of the Diagnostic and Statistical Manual of Mental Disorders, Third Edition (DSM-III) in $1980 .{ }^{65}$ Additional diagnostic refinements included the addition of pervasive developmental disorder not otherwise specified (PDD-NOS) in 1987 and inclusion of Asperger's syndrome in DSM-IV. ${ }^{66}$

The DSM diagnosis of ASD was further revised with the recent publication of $D S M-5$. ASD phenotype diagnoses of autistic disorder, Asperger's syndrome, atypical autism, and PDD-NOS were replaced with one diagnosis, namely, ASD. Additionally, the three ASD domains included in DSM-IV and International Classification of Diseases, Tenth Edition (ICD-10) (social reciprocity, communication, and restricted and repetitive behaviors) were collapsed into two domains: 1) social communication/interaction and 2) restricted and repetitive behaviors, with evidence required of persistent symptoms that cause functional impairment (currently or historically) in these two domains. Furthermore, abnormalities in sensory reactivity were added to the restricted/repetitive behavior domain. Importantly, DSM-5 acknowledges that, although symptoms must begin in early childhood, they may become more recognizable in later life with increasing social demands. The latter may be particularly relevant for individuals whose symptoms may present a different pattern or become more obvious with the complexities of adult life (eg, females ${ }^{54}$ or young people transitioning from a structured school environment to the less-structured environment of college). ${ }^{67}$

The diagnoses of childhood autism, Asperger's syndrome, atypical autism, and PDD-unspecified are still 
recognized in the ICD-10 (Table 1), although ICD-11 (expected publication date 2017) may include revisions to this classification system.

The impact of changes to the diagnostic criteria for people with ASD is yet to be established. ${ }^{68}$ However, a recent study investigating ASD diagnoses made in adulthood compared DSM-5 ASD criteria with ICD-10R and DSM-IV; while the specificity of $D S M-5$ ASD criteria was good, the sensitivity was relatively poor. ${ }^{69}$ For example, $44 \%$ of adults who received an ASD diagnosis according to ICD-10R did

Table I ICD-10 and DSM-5 diagnostic criteria for ASD

ICD-I 0 autism (F84.0)

Abnormal or impaired development is evident at the age

of $<\mathbf{3}$ years in at least one of the following areas:

I. Receptive or expressive language as used in social communication

2. The development of selective social attachments or of reciprocal social interaction

3. Functional or symbolic play

A total of at least six symptoms from (1), (2), and (3) must be present, with at least two from (I) and at least one from each of (2) and (3):

(I) Qualitative abnormalities in reciprocal social interaction are manifest in at least two of the following areas:

(a) Failure adequately to use eye-to-eye gaze, facial expression, body posture, and gesture to regulate social interaction

(b) Failure to develop (in a manner appropriate to mental age, and despite ample opportunities) peer relationships that involve a mutual sharing of interests, activities, and emotions

(c) Lack of socioemotional reciprocity as shown by an impaired or deviant response to other people's emotions; lack of modulation of behavior according to social context; or a weak integration of social, emotional, and communicative behaviors

(d) Lack of spontaneous seeking to share enjoyment, interests, or achievements with other people (eg, a lack of showing, bringing, or pointing out to other people objects of interest to the individual)

(2) Qualitative abnormalities in communication are manifest in at least one of the following areas:

(a) A delay in, or total lack of, the development of spoken language that is not accompanied by an attempt to compensate through the use of gesture or mime as an alternative mode of communication (often preceded by a lack of communicative babbling)

(b) Relative failure to initiate or sustain conversational interchange (at whatever level of language skills is present), in which there is reciprocal responsiveness to the communications of the other person (c) Stereotyped and repetitive use of language or idiosyncratic use of words or phrases

(d) Lack of varied spontaneous make-believe or (when young) social imitative play

(3) Restricted, repetitive, and stereotyped patterns of behavior, interests, and activities are manifest in at least one of the following areas:

(a) An encompassing preoccupation with one or more stereotyped and restricted patterns of interest that are abnormal in content or focus; or one or more interests that are abnormal in their intensity and circumscribed nature though not in their content or focus

(b) Apparently compulsive adherence to specific, nonfunctional routines or rituals

\section{DSM-5 ASD}

Although symptoms must begin in early childhood, they may not be recognized fully until social demands exceed capacity

I. Social communication/interaction domain: all of the following symptoms must be met:

Problems reciprocating social or emotional interaction, including difficulty in establishing or maintaining back-and-forth conversations and interactions, inability to initiate an interaction, and problems with shared attention or sharing of emotions and interests with others

Severe problems in maintaining relationships - ranges from lack of interest in other people to difficulties in pretend play and engaging in age-appropriate social activities and problems adjusting to different social expectations

Nonverbal communication problems, such as abnormal eye contact, posture, facial expressions, tone of voice and gestures, and an inability to understand these

2. Restricted and repetitive behavior domain: two of the four symptoms related to restricted and repetitive behavior must be present

Stereotyped or repetitive speech, motor movements or use of objects

Excessive adherence to routines, ritualized patters of verbal or nonverbal behavior, or excessive resistance to change 
Table I (Continued)

ICD-I 0 autism (F84.0)
(c) Stereotyped and repetitive motor mannerisms that involve
either hand or finger flapping or twisting or complex whole-body
movements
(d) Preoccupations with part-objects or nonfunctional elements of
play materials (such as their odor, the feel of their surface, or the
noise or vibration that they generate)
The clinical picture is not attributable to the other varieties
of pervasive developmental disorder: specific developmental
disorder of receptive language (F80.2) with secondary
socioemotional problems, reactive attachment disorder
(F94.I) or disinhibited attachment disorder (F94.2), mental
retardation (F70-F72) with some associated emotional or
behavioral disorder, schizophrenia (F20) of unusually early
onset, and Rett's syndrome (F84.2)

DSM-5 ASD

Highly restricted interests that are abnormal in intensity or focus

Hyper-or hyporeactivity to sensory input or unusual interest in sensory aspects of the environment

Other ASD diagnoses identified in ICD- I 0, but not in DSM-5

F84.5 Asperger's syndrome

Asperger's syndrome is characterized by the same criteria and the type of qualitative abnormalities of reciprocal social interaction and restricted, stereotyped, repetitive repertoire of interests and activities that typify autism. However, Asperger's differs from autism primarily in that there is no general delay or retardation in language or in cognitive development

F84. I Atypical autism

A type of pervasive developmental disorder that differs from childhood autism either in the age of onset or in failing to fulfill all three sets of diagnostic criteria. This subcategory should be used when there is abnormal and impaired development that is present only at the age of $>3$ years and a lack of sufficient demonstrable abnormalities in one or two of the three areas of psychopathology required for the diagnosis of autism (namely, reciprocal social interactions, communication, and restricted, stereotyped, repetitive behavior) in spite of characteristic abnormalities in the other areas. Atypical autism arises most often in profoundly retarded individuals and in individuals with a severe specific developmental disorder of receptive language

F84.9 Pervasive developmental disorder, unspecified

This is a residual diagnostic category that should be used for disorders, which fit the general description for pervasive developmental disorders but in which a lack of adequate information, or contradictory findings, means that the criteria for any of the other F84 codes cannot be met

Notes: ${ }^{a}$ For example, not speaking single words by age 2 years and not speaking communicative phrases by age 3 years. Data from ICD-I0 ${ }^{178}$ and DSM-5. ${ }^{179}$ Abbreviations: ASD, autism spectrum disorder; DSM-5, Diagnostic and Statistical Manual of Mental Disorders, Fifth Edition; ICD-I0, International Classification of Diseases, Tenth Edition.

not meet $D S M-5$ criteria for ASD. Likewise, $22 \%$ of adults who met $D S M$-IV-TR diagnostic criteria for Asperger's or autistic disorder did not meet $D S M-5$ diagnostic criteria for ASD. It is unclear how individuals whose symptoms (and functional impairment) fall within the broader spectrum of ASD according to ICD-10 and DSM-IV, but who no longer meet diagnostic criteria for ASD according to DSM-5, will be identified and cared for in the future.

Although behavioral diagnostic criteria may fluctuate, it is also important to consider potential neurobiological factors underlying symptoms and traits of ASD and their developmental consequences. For example, language delay may serve as a potential marker of atypical brain development and behavior, which is of both clinical and research utility and may conceivably enable the development of individualized treatment. ${ }^{70-72}$ According to current European diagnostic criteria, ${ }^{73}$ people with autism and Asperger's both meet symptom criteria across the three ASD domains, but people with Asperger's do not have a history of language or cognitive delay. The behavioral phenotype is underpinned by biological differences in brain in both gray matter volume $\mathrm{e}^{71,72}$ and white matter structure. ${ }^{70}$ Hence, the particular timing of language acquisition may be a possible marker of specific developmental changes in brain that may be atypical in some people with ASD. ${ }^{70,71}$ Overall, the debate about the phenomenological boundaries of autism continues. However, the outcome of this may have significant implications for translational research, novel treatment trials, personalized therapeutic options, and evidence-based service development.

\section{Health}

\section{Physical health}

Physical health and ASD

There is limited investigation of the physical health of adults with ASD. However, a recent retrospective review of health records (1,507 adults with ASD and 15,070 adults without ASD) found that adults with ASD had significantly increased rates of both mental (depression, anxiety, bipolar affective 
disorder, obsessive-compulsive disorder [OCD], psychosis, and self-harm) and physical (sleep, immune and gastrointestinal [GI] disorders, obesity, hyperlipidemia, hypertension, seizures, cerebrovascular accidents, and Parkinson's disease) health problems. ${ }^{74}$ Similarly, higher rates of seizures, hypertension, and allergies have been reported in smaller samples of adults with ASD, along with lower rates of sexually transmitted diseases, smoking, and alcohol misuse. ${ }^{75}$ Importantly, adults with ASD were also found to have the same risks of developing some common - and treatable health conditions as the general population: hypothyroidism, hyperlipidemia, constipation, and urinary incontinence. Furthermore, high rates of poor health have been identified among young adults with ASD (34\% obesity, 31\% hyperlipidemia, and $19 \%$ hypertension), thereby placing them at increased risk of developing diabetes, heart disease, and cancer in later life. ${ }^{76}$

Despite having common and treatable health conditions, adults with ASD report difficulty in accessing health care. ${ }^{77}$ Crucially, physicians report a lack of awareness of ASD, particularly those providing care for adults. ${ }^{78}$ Overall, the findings underline the importance of providing readily accessible evidence-based, age-appropriate primary and hospital health care for adults with ASD. This may be facilitated by a twofold approach: raising awareness in health professionals about ASD in adults and their susceptibility to increased rates of some mental and physical health disorders ${ }^{79}$ but also encouraging health professionals to look beyond the diagnosis of ASD and to consider the everyday health needs of adults with ASD as they would for people who do not have ASD.

Overall, there is a dearth of research regarding the physical health of adults with ASD. As such, we review three health problems reported by children and adults with ASD, but using available (pediatric) literature: sleep, GI problems, and epilepsy. It is hoped that this may generate both future health research and development of health services for adults with ASD.

\section{Sleep}

Sleep problems are commonly reported in children with ASD and typically include difficulties with sleep onset, settling, and night waking. ${ }^{80,81}$ There has been little investigation of sleep in adults with ASD, although there is preliminary evidence of subjective insomnia ${ }^{82,83}$ and polysomnograph findings of increased sleep latency and night wakings in ASD adults. ${ }^{84}$ It has been suggested that abnormalities in melatonin production and circadian timing may contribute to insomnia and circadian sleep disturbances in people with ASD ${ }^{81}$ However, other health variables (medication, obesity, epilepsy, GI problems, ${ }^{80}$ mood, and anxiety ${ }^{83}$ ) may also contribute to poor sleep in people with ASD. ${ }^{80}$

The Autism Treatment Network (ATN) and the National Initiative for Children's Healthcare Quality have developed an expert clinical consensus pathway regarding the assessment and management of insomnia in young people (but not adults) with ASD. ${ }^{85}$ This includes recommendations that all young people with ASD should be screened for insomnia and possible associated factors and, if treatment is indicated, it should include parent training, consideration of medication, and follow-up to determine efficacy. There is preliminary evidence that melatonin can be effective in treating insomnia in ASD children, ${ }^{86}$ but sleep assessment and treatment trials in ASD adults are warranted. Overall, although sleep should be included in health reviews of people with ASD, greater understanding of the causes, treatment, and age trajectories of poor sleep are required. ${ }^{80,81}$

\section{GI}

GI problems are one of the most commonly reported health concerns for children with ASD, although prevalence rates and treatment options are poorly understood. ${ }^{87}$ High rates of GI and other health problems have been recently reported in adults with ASD. ${ }^{74}$ However, there is little specific investigation of GI disorders in ASD adults. A recent meta-analysis found that, in comparison with non-ASD children, ASD children have a threefold elevated risk of GI complaints, constipation, and diarrhea and a twofold elevated risk of abdominal pain. ${ }^{88}$ The ATN has released guidelines regarding management of constipation in young people with ASD. ${ }^{89}$

Furthermore, feeding and eating problems are five times more common in ASD children and may contribute to GI difficulties. ${ }^{90}$ For example, food selectivity (eating a highly limited range of food or just one food) may be associated with poor nutrition, altered gut motility, and constipation in people with ASD. ${ }^{90,91}$ Recently published nutritional guidelines for the management of GI symptoms in ASD children advise that poor nutrition may be contributed to by restricted dietary choices (restriction or elimination diets) imposed by carers. ${ }^{91}$ Although data are limited, a small randomized, double-blind, crossover study of 15 children (2-16 years old) with ASD on gluten- and casein-free diets found no significant change in ASD symptoms. ${ }^{92}$ However, despite any absence of evidence supporting their efficacy, children with developmental disorders are more likely to be placed on restricted or elimination diets by their carers. ${ }^{91,93}$ 
Additionally, social communication difficulties (and associated health problems, such as anxiety) may make reporting of physical symptoms difficult for some people with ASD. Hence, clinicians should consider whether changes in, or exacerbations of, behavior such as altered sleep patterns, irritability, anxiety, or self-injury may be indicative of physical problems. ${ }^{88}$ Consensus recommendations from an expert panel of gastroenterologists emphasize the need for increased research and evidence-based clinical care ${ }^{87}$ However, they also contain the important proviso that clinicians should expect to see at least the same rate of GI problems in people with ASD as they see in people who do not have ASD and should provide appropriate assessment and treatment accordingly.

\section{Epilepsy}

Many studies report that people with ASD have an increased risk of epilepsy, although rates vary widely from $2 \%$ to $46 \%{ }^{94}$ This variability may be due in part to methodological differences, including study inclusion criteria and rigor of diagnosis of both ASD and epilepsy. ${ }^{94,95}$ However, a recent review identifies female sex and learning disabilities as risk factors for epilepsy in people with ASD.${ }^{94}$ To date, no seizure types are particularly associated with ASD, and there are no treatment reviews available regarding the treatment of seizures in people with ASD. However, there are concerns regarding both under and overdiagnosis of epilepsy in people with ASD. ${ }^{94,96}$ As such, it is recommended that people with ASD and possible seizures are referred to neurologists for review, that electroencephalograms (EEGs) are performed only if there is clinical concern about seizures, ${ }^{94}$ and that sleep ${ }^{96}$ and metabolic disorders ${ }^{97}$ are considered in the assessment and management of seizures in people with ASD.

\section{Mental health}

\section{Mental health and ASD}

Although the mental health needs of adults with ASD are less well characterized than those of children with ASD, there is evidence that adults with ASD have significantly increased rates of mental health problems, including mood and anxiety disorders, $,{ }^{6,9899} \mathrm{OCD},{ }^{100}$ attention-deficit hyperactivity disorder (ADHD), ${ }^{101}$ and psychotic disorders. Furthermore, these comorbid mental health difficulties persist from childhood to adulthood ${ }^{102}$ and occur in both males and females with ASD. ${ }^{54,103}$ Moreover, people with ASD can have specific cognitive anomalies, including poor planning, decision making, timing, and motor skills, ${ }^{104-107}$ which may adversely impact on their everyday living skills ${ }^{108}$ and ability to access health services.

\section{ADHD in people with ASD}

Difficulties with attention are common in people with ASD, including problems with switching attention and sustained (focused) attention. ${ }^{109-111}$ It has been suggested that attention problems are part of the cognitive phenotype of $\mathrm{ASD}^{112}$ and have significant implications for the diagnosis and management of ASD and associated mental health difficulties. ${ }^{113}$ According to DSM-IV and ICD-10 guidelines, an individual with ASD cannot also be diagnosed with ADHD. However, there is increasing recognition that ADHD is common in people with $\mathrm{ASD}^{106}$ and persists from childhood to adulthood, ${ }^{102}$ and $D S M-5$ does allow for the diagnosis of both ASD and ADHD in one person. Furthermore, adults with ASD are aware of having difficulties with attention and appropriately rate their ADHD symptoms using the Barkley ADHD questionnaire. ${ }^{101}$

There is preliminary evidence that children with ASD and comorbid ADHD can benefit from treatment of ADHD, including stimulant medication, ${ }^{114}$ atomoxetine, ${ }^{115}$ and psychological management. ${ }^{116}$ However, some young people with ASD may respond poorly to medication for $\mathrm{ADHD}^{117}$ or have increased side effects. ${ }^{116}$ For example, in a randomized control trial of methylphenidate in children with ASD and ADHD, ${ }^{117} 49 \%$ had a therapeutic response (compared with a $69 \%$ response rate in children with ADHD in the Multimodal Treatment Study of Children with ADHD (MTA) study. ${ }^{118}$ Furthermore, $18 \%$ of children with ASD discontinued medication because of side effects, including irritability, loss of appetite, emotional outbursts, and poor sleep (compared to $1.4 \%$ of children with ADHD in the MTA study).

The Autism Speaks ATN Psychopharmacology Committee has provided a clinical pathway for the assessment and management of ADHD in children and adolescents with ASD. ${ }^{119}$ Because of the limited available evidence to date, these are primarily based on expert clinical consensus but provide guidance on evaluation of symptoms of ADHD in children with ASD and, where indicated, choice of medication. The ATN pathway recommends evaluation of both ASD and ADHD using validated assessments, gathering collateral history across settings (family/school) where available, and consideration of behavioral, environmental, and medical factors (including GI, seizures, and anxiety) that may be contributing to poor attention. If ADHD is confirmed, short-acting methylphenidate is recommended as the firstline pharmacological treatment of ADHD in young people with ASD, with careful clinician monitoring for efficacy and possible side effects and exclusion of any cardiac problems prior to the initiation of stimulants. ${ }^{119}$ 
To the best of our knowledge, no published evidence is yet available regarding pharmacological or psychological treatment of ADHD in adults with ASD. As such, best practice guidelines (recommendations for clinicians about the care of patients with specific conditions, based upon the best available research evidence and practice experience) should apply (Table 2), including liason of primary care and community physicians with psychiatrists and psychologists experienced in prescribing and providing psychological management for adults with ASD and ADHD.

Furthermore, there is a debate regarding whether people with ASD, ADHD, or combined ASD and ADHD have shared or different neurobiology. This is important, as an increased understanding of the causal mechanisms underlying specific symptoms may contribute to future development of individually tailored treatments. For example, recent novel functional magnetic resonance imaging (fMRI) studies have found both shared and disorder-specific brain differences in youth with ASD and ADHD across fMRI tasks of sustained attention ${ }^{120}$ and reward-related temporal discounting. ${ }^{121}$ Further studies are warranted to better understand the neurobiology of ASD and common comorbidities, which may enable the development of more personalized treatments.

\section{Mood disorders, anxiety, and OCD in people with ASD}

Affective disorders, including depression, ${ }^{99}$ anxiety, ${ }^{98}$ and OCD,${ }^{100}$ are common in adults with ASD (across both sexes). ${ }^{54}$ For example, high rates of depression and anxiety were identified in adults with Asperger's syndrome in Sweden; of the 26 men and 28 women studied, $70 \%$ had at least one episode of major depression, $50 \%$ had recurrent depressive episodes, and $50 \%$ had anxiety disorders, although psychosis and substance

Table 2 Maudsley Hospital National Autism Service recommendations for good prescribing practice in adults with ASD

I. Start medication at low doses

2. Gradually titrate to maximal efficacy with regular monitoring for side effects and individual response to medication targets (eg, use of mood, ADHD, and OCD rating scales)

3. Health monitoring before the initiation of, and during the use of, medication as appropriate (eg, cardiac review if patient/family cardiac history before methylphenidate initiation and lipid/weight monitoring with antipsychotics)

4. Stop any aversive or ineffective medication

5. Discuss medication/seek an expert second opinion as indicated

6. Avoid polypharmacy

7. Schedule planned reviews, including whether to continue or stop the medication

Abbreviations: ADHD, attention-deficit hyperactivity disorder; ASD, autism spectrum disorder; $\mathrm{OCD}$, obsessive-compulsive disorder. use were uncommon..$^{99}$ More recently, a retrospective review of clinical assessments of 474 adults with ASD found that $58 \%$ had at least one other psychiatric diagnosis (typically anxiety disorders, OCD, depression, and ADHD). ${ }^{103}$

Despite high rates of anxiety in ASD adults, including generalized anxiety, social anxiety, phobias, and OCD, ${ }^{100,122}$ anxiety is often overlooked and assumed to be part of an ASD profile, rather than warranting a separate diagnosis, which can limit access to treatment. However, there is evidence that assessment instruments validated for the assessment of OCD have direct clinical utility in the assessment of OCD in adults with ASD. For example, 40 male and female adults with high-functioning ASD and 45 sex-matched adults with OCD completed the Yale-Brown Obsessive-Compulsive Scale (Y-BOCS) symptom checklist; $25 \%$ of the ASD adults met Yale-Brown Obsessive-Compulsive Scale and ICD-10 diagnostic criteria for OCD. ${ }^{100}$ Additionally, the type of OCD symptoms differed across diagnoses; adults with ASD + OCD reported more sexual obsessions than OCD adults, who reported more somatic obsessions. Recent evidence suggests that adults with ASD + OCD engage in significantly more checking, ordering, and obsessive behaviors than people with ASD without OCD and also order and hoard more than people with OCD. ${ }^{123}$ Additionally, self-report measures of OCD (Obsessive-Compulsive Inventory-Revised) appear to be useful in screening adults with $\mathrm{ASD}^{123}$ and so may be a valuable and cost-effective triage tool for adult ASD mental health services.

OCD is, by definition, intrusive, distressing, and time-consuming to the individual and their family. OCD is ranked by the World Health Organization as a top 20 cause of years lived with disability; ${ }^{124}$ barriers to care that contribute to this ranking include lack of knowledge and poor access to treatment. However, there is evidence that psychological treatments adapted for people with ASD can provide effective treatment of OCD and anxiety in adults with $\mathrm{ASD}^{125}$ and, crucially, that treatment gains are maintained. ${ }^{31}$ Hence, although repetitive behaviors are characteristic of ASD, it is important not to presume that adults with ASD cannot also have OCD or other comorbid (and treatable) difficulties. Failure to accurately diagnose symptomatology that is present may lead to inadequate treatment and increased morbidity.

In summary, adults with ASD commonly experience comorbid mental health difficulties.$^{98}$ However, to date, access to ASD diagnostic and management services to enable identification and treatment of these disabling conditions is extremely limited. ${ }^{5}$ There is an urgent need for increased 
awareness of ASD, assessment of associated health difficulties, clinical treatment trials, and development of evidencebased health care for males and females with ASD across the adult lifespan.

\section{Service development Recommendations for assessment of ASD}

In the UK, the National Institute for Health and Care Excellence (NICE) provides evidence-based guidelines (available online) regarding the assessment and management of a variety of physical and mental conditions, including the care of adults with ASD. ${ }^{126}$ Although developed for the UK, these first recommendations can be adapted for international use and provide a benchmark of appropriate care for newly developing adult ASD services.

For example, NICE recommends that adults referred for assessment of ASD should have a comprehensive, multidisciplinary assessment by trained professionals, which includes diagnosis (assessment of core ASD difficulties, early development, medical and family history, behavior, education, and employment), needs assessment, risks, and feedback to the individual. Where possible, a collateral neurodevelopmental history should be obtained from parents/carers who have known the individual well since early childhood.

If resources allow, NICE recommends the use of validated assessment tools to contribute structure and validity to diagnostic assessments, such as the Autism Diagnostic InterviewRevised (ADI-R), ${ }^{127}$ the Autism Diagnostic Observation Schedule-Generic (ADOS), ${ }^{128}$ the Diagnostic Interview for Social and Communication Disorders, the Asperger's Syndrome (and high-functioning autism) Diagnostic Interview, and the Ritvo Autism Asperger Diagnostic ScaleRevised. The ADI-R and ADOS significantly contributed to the scientific investigation of ASD by providing robust, reliable, and validated ASD assessment criteria, have been adopted as gold standard ASD assessment tools, ${ }^{61,129}$ and are also specifically recommended for assessment of ASD in people with LD. ASD screening questionnaires available for use with adults include the Social Responsiveness Scale ${ }^{130,131}$ and the Autism Quotient (AQ), ${ }^{132}$ although a recent comparison of the $A Q$ with expert clinical diagnostic consensus (ICD-10, ADI-R and ADOS) found the AQ had limited specificity. ${ }^{133}$ Similarly, screening questionnaires for other common mental health comorbidities (eg, the Barkley measure of ADHD or the Obsessive-Compulsive InventoryRevised) can contribute to the provision of comprehensive health services for adults with ASD, including both initial assessment and monitoring of response to treatment.

The NICE guidelines also include a range of recommendations for adult service provisions, including care planning, risk assessment (to self and from others), challenging behavior, health passports, crisis plans, second opinions, and meeting social and educational needs.

As with any condition where multiple etiologies and/or comorbid difficulties are possible, an adequate assessment of ASD should include a full medical history, physical examination, and consideration of known genetic associations with ASD, such as 22q11.2 deletion syndrome, ${ }^{134}$ fragile $\mathrm{X}$ syndrome, and tuberous sclerosis. Additional medical investigations and liason with appropriate physicians are recommended where appropriate (Table 3 ).

However, the behavioral assessment of ASD can be time-consuming and expensive and, in the absence of biomarkers, relies on expert clinical assessment that is not always available. ${ }^{6}$ As such, tools to improve accuracy, speed, cost, and availability of assessment of ASD are important. Innovative brain magnetic resonance imaging (MRI) diagnostic classification analysis has provided preliminary evidence that neuroimaging may aid the behavioral diagnosis of ASD. ${ }^{135}$ For example, Ecker et al demonstrated that adults with ASD may be distinguished from typically developing adults using neuroanatomical brain scans at an overall

Table 3 Maudsley Hospital National Autism Service recommendations for medical investigations for adults with ASD

I. Genetic investigation: history of dysmorphic features, congenital anomalies, associated physical health problems (eg, cardiac, metabolic, skeletal, and immune), learning difficulties, or family medical history

2. Metabolic investigation: history consistent with anxiety or mood disorder or cramps/leg pains (eg, thyroid and calcium levels)

3. Hematological: history consistent with anxiety or mood disorder

4. Blood monitoring (eg, monitoring of health with psychotropic medication and lipids and drug levels of prescribed medication)

5. Cardiac: eg, ECG/cardiac review prior to starting medication if personal or family cardiac history prior to starting stimulants for ADHD, blood pressure monitoring for people prescribed stimulant medication for ADHD, and echocardiography for all people diagnosed with 22 q I I.2 deletion syndrome ${ }^{134}$

6. Neurological: eg, EEG for possible epilepsy, brain MRI if indicated

7. Renal: renal ultrasound for all people diagnosed with 22 q I I.2 DS. ${ }^{134}$

8. Immunology: eg, if recurrent infections

Abbreviations: ADHD, attention-deficit hyperactivity disorder; ASD, autism spectrum disorder; ECG, electrocardiogram; EEG, electroencephalogram; DS, deletion syndrome; MRI, magnetic resonance imaging. 
accuracy of $80 \%-90 \%$. This awaits replication in a clinical setting, but it raises the possibility that MRI brain scans may contribute to objective, accurate, and time-effective assessment of ASD in the future.

\section{Medication}

Despite the increasing prevalence of ASD and associated costs, ${ }^{19}$ no medication is approved for the treatment of either core symptoms or comorbid mental health difficulties in adults with ASD. ${ }^{136}$ Although there is more available evidence for psychotropic use in children with ASD than adults, overall there is a lack of treatment trials and guidance. However, both risperidone and aripiprazole are approved by the Food and Drug Administration for the treatment of irritability in young people with ASD in the USA. In the UK, NICE recommends that medication options for adults with autism and associated psychiatric comorbidity are informed by existing NICE guidelines for the associated condition (eg, ADHD/OCD).

Despite the lack of treatment trials, there is evidence that people with ASD are more likely to be prescribed psychotropic medication (primarily sleep medication, stimulants, antidepressants, and antipsychotics) ${ }^{137}$ than the general population. ${ }^{138}$ Furthermore, psychotropic medication is increasingly prescribed for young people and adults with ASD; in Carolina, $30 \%-45 \%$ of people with ASD are now prescribed medication. ${ }^{137}$ However, prescribing rates do vary internationally; ${ }^{139,140}$ prescribing rates of psychotropics for people with ASD in the UK appear more conservative (29\%), although polypharmacy still occurs. ${ }^{138}$

Crucially, once people with ASD are prescribed medication, it is continued. Remarkably, they are eleven times more likely than those without ASD to remain on psychotropic medication and nearly five times more likely to remain on nonpsychotropic medication, ${ }^{137}$ suggesting either considerably increased rates of health problems requiring medication or poor physical and mental health care that lacks medication review.

It has been suggested that some people with ASD are vulnerable to medication side effects, including reduced efficacy, toxicity, and idiosyncratic response to medication (NICE 2012). ${ }^{117,119}$ The National Autism Service at the Maudsley Hospital has been providing specialist in- and outpatient clinical mental health services for ASD adults for over 20 years. In the absence of any available guidelines, Table 2 summarizes the recommended good practice used by the authors and colleagues at The Maudsley Hospital, National Autism Service, when prescribing for adults with ASD.
Overall, research is urgently needed to increase the understanding of response to available medication, develop new individualized therapeutic options, identify valid and reliable outcome measures, and determine best practice guidelines for adults with ASD. ${ }^{141}$ It is hoped that recent international multidisciplinary collaborations will enable the development of bench to bedside novel therapeutic options that may include consideration of both genetic and neurobiological causes of ASD and comorbid difficulties and response to treatment. For example, European Autism Interventions - A Multicentre Study for Developing New Medications (EUAIMS) is a multicenter, European-wide autism initiative to develop novel therapeutic options, develop expert clinical sites, and provide a shared knowledge platform for people with ASD and professionals. ${ }^{142}$

\section{Psychological management}

There are few rigorous studies investigating the effectiveness of psychosocial interventions ${ }^{143}$ or cognitive behavioral therapy (CBT) in adults with $\mathrm{ASD} .{ }^{21}$ To date, there is one randomized control trial ${ }^{31}$ of modified CBT for treatment of OCD/anxiety in adults with ASD (finding good treatment response and maintenance over 12 months) and a preliminary investigation of mindfulness (finding significant reduction in anxiety, depression, and ruminations). ${ }^{144}$ A randomized, controlled open trial of CBT and recreational activity in adults with ASD found no significant difference between interventions in measurements of quality of life, although CBT participants rated themselves as more improved in expressing needs and understanding difficulties. ${ }^{145}$ An uncontrolled 18-month trial of cognitive enhancement therapy (rehabilitation of social and nonsocial cognitions) in 14 adults with ASD reported participant satisfaction and significant improvement of cognitive and social outcomes. ${ }^{146}$ Overall, much remains to be done to determine the most efficacious evidence-based psychological treatments for associated difficulties of adults with ASD. ${ }^{31,145}$

\section{Transition}

There is increasing recognition of the need for young people with neurodevelopmental disorders to have a planned transition from child to adult health services (NICE 2012) (77,147 $^{6}$ but very limited investigation of how best to do this. ${ }^{148,149}$ Differential funding of child and adult services, differing eligibility criteria for care and limited awareness among physicians ${ }^{78}$ and other professionals of adult neurodevelopmental disorders may contribute to mismatched resources. Young adults with ASD may therefore become lost to health 
care at an important time of increased vulnerability on transition from adolescent to adult health and education systems. Perhaps not surprisingly, many professionals and families feel confused about how to navigate the system between child and adult services. ${ }^{150}$

To date, there has been little investigation of the transition of young people with ASD to adult services. Consensus guidelines regarding transitions for young adults with specials care health needs have been available for the last decade. ${ }^{151}$ However, there remains a lack of clear pathways providing planned and informed transition between child and adult services for people with ASD. Furthermore, successful transition requires adaptive skills that can be learned and adapted for use across future transitions. For example, in addition to moving from child to adult services, transitions occur naturally across many life events: adult relationships, parenthood, employment, death of a parent/ carer. There is increasing recognition from both people with $\mathrm{ASD}^{7}$ and professionals ${ }^{149}$ of the need for transition services to also consider lifelong functioning and adaptive skills. Despite this, young people with ASD are 64\% less likely than other youth with special health care needs to receive transition services to adult care. ${ }^{148}$ Furthermore, there is preliminary evidence that access to transition services for young people with ASD can be more problematic for those from ethnic minorities, with behavioral difficulties or anxious parents. ${ }^{152}$

\section{Older adults}

Little is known of the mental and physical health of older adults with ASD. ${ }^{10,153}$ However, an increasing number of older adults are being diagnosed with ASD, and future research should include the determination of mental and physical health in older adults with ASD, including dementia, development of age-appropriate treatment options, and consideration of social and financial factors. For example, the death of a parent, partner, or older sibling who has been caring for an older adult with ASD may adversely impact on their mental health and ability to live independently.

There is first evidence of increased rates of Parkinsonism in adults ( $\geq 49$ years old) with ASD. ${ }^{154}$ Following neurological examination and use of the Movement Disorder Society-Unified Parkinson's Disease Rating Scale, 20\% of adults with ASD were found to have Parkinsonism (including rigidity of tone, bradykinesia, resting tremor, and postural instability). ${ }^{154}$ Although the findings are preliminary, if confirmed, they have significant implications both for understanding the neurobiology of ASD and the development of age-specific health services for adults with ASD. Furthermore, there is preliminary evidence of an increased risk of early onset age-related disease in genetically determined neurodevelopmental disorders that are associated with ASD, for example, early onset Alzheimer's in Down syndrome ${ }^{155}$ and preliminary evidence of early onset Parkinson disease in 22q11.2 deletion syndrome. ${ }^{156,157}$ Further research is warranted to investigate the health of older adults with $\mathrm{ASD}^{10}$ and to determine possible genetic vulnerability toward agerelated disease.

\section{Brain development across the lifespan in ASD}

ASD is a lifelong neurodevelopmental disorder. Brain imaging studies offer the opportunity for greater understanding of brain development and associated behavioral difficulties across the lifespan of people with ASD, which may contribute to the development of age-appropriate treatments. ${ }^{158}$ For example, there is accumulating longitudinal evidence of abnormal, age-related changes in the brain anatomy of individuals with ASD in comparison to typically developing individuals, particularly in frontotemporal and striatal regions in early childhood ${ }^{159-161}$ and adolescence. ${ }^{162}$ Furthermore, there is increasing cross-sectional evidence of region-specific and age-related changes in the brain structure of people with ASD from childhood to adulthood across a number of areas associated with ASD symptoms, including parameters of volume (cerebellum, ${ }^{3}$ amygdala, ${ }^{163}$ and striatum $^{164}$ ) and surface-based measures of cortical thickness and surface area (medial frontotemporal ${ }^{165}$ and parietal regions ${ }^{166}$ ). Earlier brain imaging investigations in people with ASD suggested that macrocephaly (head circumference $\geq 97$ th centile for age and sex) may be a risk factor in the development of ASD. ${ }^{167}$ However, more recent investigations in larger samples have questioned this ${ }^{168}$ and suggested that true brain overgrowth occurs only in a small subgroup of ASD children. ${ }^{158,169}$

To date, there is a limited fMRI investigation of functional brain maturation in people with ASD. However, there is fMRI evidence that sustained attention brain networks in people with ASD are activated abnormally and, furthermore, that this is associated with abnormal functional brain maturation of fronto-striatal-cerebellar attention networks between late childhood and adulthood in people with ASD. ${ }^{170}$ Abnormal activation and maturation of attention networks may contribute to attention difficulties across the lifespan ${ }^{101,102}$ and the associated costs of ASD, such as loss of earnings/employment or education. ${ }^{19}$ However, to 
date, there is limited longitudinal investigation of brain maturation in people with ASD from childhood through adulthood.

Future developmental investigations are warranted to enable better understanding of brain, cognition, and behavior in people with ASD across the lifespan, identify biomarkers, and develop effective age-appropriate, personalized treatments.

\section{Neurochemistry}

There is evidence that ASD adults have differences in brain chemistry, which may contribute both to ASD symptoms and differential response to treatment. Three neurotransmitter systems have been a focus of current investigation: gamma aminobutyric acid (GABA), glutamine, and serotonin. In brief, GABA plays a central role in both neurodevelopment and inhibitory neurotransmission and binds differentially in adults with ASD. ${ }^{171}$ Conversely, glutamatergic (excitatory) neurotransmission appears to be enhanced, ${ }^{9}$ while serotonin anomalies have been associated with the recognition of emotion and response inhibition in adults with ASD. ${ }^{172,173}$

Crucially, serotonin levels may be modifiable and so may offer opportunities for future treatment development. For example, an fMRI investigation of the neural processing of facial emotions found that modulation of serotonin levels normalized the brain activation patterns of ASD adults in social brain regions (including frontal lobe, lingual gyrus, and limbic areas) to that of typically developing controls. ${ }^{173}$ Similarly, fMRI studies of serotonin modulation in tasks of impulsivity and inhibition found normalization of brain activation of ASD adults in key brain inhibition regions (frontal, striatal, and cerebellar). ${ }^{172}$ Positron emission tomography studies have reported abnormalities in both serotonin and dopamine transporter binding in adults with ASD. ${ }^{174}$

In addition to its better known hormonal role in facilitating uterine contractions and milk let down, oxytocin also acts as a neuromodulator and is thought to be implicated in social cognition. Although results of early oxytocin trials are mixed, ${ }^{175}$ there is preliminary evidence that intransal doses of oxytocin are associated with improved empathy and reduced repetitive behaviors in adults with ASD. ${ }^{176}$ Furthermore, a 12-week modified maximum tolerated dose study of oxytocin in 15 young people with ASD found that daily administration of oxytocin was well tolerated, with no reported serious adverse events, and was associated with some changes in measures of social cognition, repetitive behavior, and anxiety. ${ }^{177}$
Overall, translational work is urgently required to better understand the potential relationship between brain chemistry and behavior in people with ASD and to facilitate the development of safe new treatments for adults with ASD.

\section{Conclusion}

There has been a considerable increase in ASD research over the last 20 years but much remains to be done in health services research for people with ASD. In particular, research is required to determine a better understanding of the needs of adults with ASD, including health, aging, service development, transition, treatment options across the lifespan, sex differences, and the views of people with ASD. Significant legislative efforts have been put in place internationally to increase community and professional awareness of ASD in adults and to develop community diagnostic and management services for adults with ASD. However, the outcomes of this legislation remain to be determined. Further research is required to identify evidence-based and cost-effective models of care and to enable adults with ASD to easily access coordinated, high-quality local health and social care. Additionally, future work is warranted at both ends of adulthood in ASD: improved transition from youth to adult health care and increased understanding of aging and health in older adults with ASD.

\section{Acknowledgments}

This work was supported by a grant (to Professor DG Murphy) from the EU Innovative Medicines Initiative AIMS network (receiving support from the Innovative Medicines Initiative Joint Undertaking under Grant agreement 115300, which includes financial contributions from the European Seventh Framework Programme [FP7/2007-2013] and from the European Federation of Pharmaceutical Industries and Associations), and a grant (to Professor DG Murphy) from the Sackler Institute for Translational Neurodevelopment. C Ellie Wilson is supported by the Talentia Postdoc Grant from the Agencia Andaluza del Conocomiento, Junta de Analducia. This study represents the independent research part funded by the National Institute for Health Research (NIHR) Biomedical Research Centre at South London and Maudsley, NHS Foundation Trust, and King's College London. Grainne McAlonan receives salary support from the NIHR Mental Health Biomedical Research Centre at South London and Maudsley, NHS Foundation Trust, and King's College London.

\section{Disclosure}

The views expressed are those of the authors and not necessarily those of the NHS, the NIHR, or the Department of 
Health. The authors report no other conflicts of interest in this work.

\section{References}

1. DSM-5. Diagnostic and Statistical Manual of Mental Disorders Washington. Arlington, VA: American Psychiatric Association; 2013.

2. WHO. The ICD-10 Classification of Mental and Behavioural Disorders: Diagnostic Criteria for Research. Geneva: WHO; 1993.

3. Courchesne E, Campbell K, Solso S. Brain growth across the life span in autism: age-specific changes in anatomical pathology. Brain Res. 2011; 1380:138-145.

4. Howlin P,Moss P. Adults withautism spectrum disorders. CanJPsychiatry. 2012;57(5):275-283.

5. Lake JK, Perry A, Lunsky Y. Mental health services for individuals with high functioning autism spectrum disorder. Autism Res Treat. 2014; 2014:502420.

6. Murphy DG, Beecham J, Craig M, Ecker C. Autism in adults. New biologicial findings and their translational implications to the cost of clinical services. Brain Res. 2011;1380:22-33.

7. Pellicano E, Dinsmore A, Charman T. What should autism research focus upon? Community views and priorities from the United Kingdom. Autism. 2014;18(7):756-770.

8. Shattuck PT, Roux AM, Hudson LE, Taylor JL, Maenner MJ, Trani JF. Services for adults with an autism spectrum disorder. Can J Psychiatry. 2012;57(5):284-291.

9. Ecker C, Spooren W, Murphy D. Developing new pharmacotherapies for autism. J Intern Med. 2013;274(4):308-320.

10. Piven J, Rabins P. Autism-in-Older Adults Working Group. Autism spectrum disorders in older adults: toward defining a research agenda. J Am Geriatr Soc. 2011;59(11):2151-2155.

11. Asperger H. Die "Autistischen Psychopathen" im Kindesalter. Arch Psychiatr Nervenkr. 1944;117:76-136.

12. Kanner L. Autistic disturbances of affective contact. Nervous Child. 1943;2:217-250.

13. Baio J. Centers for Disease Control and Prevention (CDC). Prevalence of autism spectrum disorders - Autism and Developmental Disabilities Monitoring Network, 14 sites, United States, 2008. Surveill Summ. 2012; 61(SS03):1-19.

14. Lotter V. Epidemiology of autistic conditions in young children. Social Psychiatry. 1966;1(3):124-135.

15. Simonoff E, Pickles A, Charman T, Chandler S, Loucas T, Baird G. Psychiatric disorders in children with autism spectrum disorders: prevalence, comorbidity, and associated factors in a population-derived sample. J Am Acad Child Adolesc Psychiatry. 2008;47(8):921-929.

16. Baird G, Simonoff E, Pickles A, et al. Prevalence of disorders of the autism spectrum in a population cohort of children in South Thames: the Special Needs and Autism Project (SNAP). Lancet. 2006; 368(9531):210-215.

17. Brugha TS, McManus S, Bankart J, et al. Epidemiology of autism spectrum disorders in adults in the community in England. Arch Gen Psychiatry. 2011;68(5):459-465.

18. Taylor I. Access to Social Care for Adults with Autism Spectrum Conditions. London: Social Care Institute for Excellence; 2011.

19. Buescher AVS, Cidav Z, Knapp M, Mandell DS. Costs of autism spectrum disorders in the United Kingdom and the United States. JAMA Pediatr. 2014;168(8):721-728.

20. Cadman T, Eklund H, Howley D, et al. Caregiver burden as people with autism spectrum disorder and attention-deficit/hyperactivity disorder transition into adolescence and adulthood in the United Kingdom. J Am Acad Child Adolesc Psychiatry. 2012;51(9):879-888.

21. Spain D, Sin J, Chalder T, Murphy D, Happe F. Cognitive behaviour therapy for adults with autism spectrum disorder and psychiatric co-morbidity: a review. Res Autism Spectr Disord. 2015;9:151-162.

22. Ecker C, Murphy D. Neuroimaging in autism - from basic science to translational research. Nat Rev Neurol. 2014;10(2):82-91.
23. Gernsbacher MA, Dawson M, Goldsmith HH. Three reasons not to believe in an autism epidemic. Curr Dir Psychol Sci. 2005;14(2): $55-58$.

24. Fombonne E. Epidemiology of pervasive developmental disorders. Pediatr Res. 2009;65(6):591-598.

25. Hansen SN, Schendel DE, Parner ET. Explaining the increase in the prevalence of autism spectrum disorders: the proportion attributable to changes in reporting practices. JAMA Pediatr. 2015;169(1):56-62.

26. Lundström S, Reichenberg A, Anckarsäter H, Lichtenstein P, Gillberg C. Autism phenotype versus registered diagnosis in Swedish children: prevalence trends over 10 years in general population samples. BMJ. 2015;350:h1961.

27. United Nations General Assembly. World Autism Awareness Day 2007. New York, NY: United Nations General Assembly; 2007. [No. 62/139 9A/RES/62/139].

28. WHO. Autism Spectrum Disorders and Other Developmental Disorders: From Raising Awareness To Building Capacity 2013. Geneva: WHO; 2013.

29. AutismSpeaks [webpage on the Internet]. Medicines for Treating Autism's Core Symptoms. Available from: http://www.autismspeaks. $\mathrm{org} /$ what-autism/treatment/medicines-treating-core-symptoms. Accessed February 11, 2016.

30. NICE [webpage on the Internet]. Quality Standard 51(QS51): Treating the Core Features of Autism: Medication; 2014. Available from: http://www.nice.org.uk/guidance/qs51/chapter/quality-statement6-treating-the-core-features-of-autism-medication. Accessed February 11, 2016.

31. Russell AJ, Jassi A, Fullana MA, et al. Cognitive behavior therapy for comorbid obsessive-compulsive disorder in high-functioning autism spectrum disorders: a randomized controlled trial. Depress Anxiety. 2013;30(8):697-708.

32. Pellicano E. The development of core cognitive skills in autism: a 3-year prospective study. Child Dev. 2010;81(5):1400-1416.

33. Bettelheim B. The Empty Fortress: Infantile Autism and the Birth of the Self. New York, NY: Free Press; 1967.

34. Folstein S, Rutter M. Infantile autism: a genetic study of 21 twin pairs. J Child Psychol Psychiatry. 1977;18(4):297-321.

35. Blomquist HK, Bohman M, Edvinsson SO, et al. Frequency of the fragile X syndrome in infantile autism. A Swedish multicenter study. Clin Genet. 1985;27(2):113-117.

36. Freitag $\mathrm{CM}$. The genetics of autistic disorders and its clinical relevance: a review of the literature. Mol Psychiatry. 2007;12(1):2-22.

37. Hallmayer J, Cleveland S, Torres A, et al. Genetic heritability and shared environmental factors among twin pairs with autism. Arch Gen Psychiatry. 2011;68(11):1095-1102.

38. Glasson EJ, Bower C, Petterson B, de Klerk N, Chaney G, Hallmayer JF. Perinatal factors and the development of autism: a population study. Arch Gen Psychiatry. 2004;61(6):618-627.

39. Maramara LA, He W, Ming X. Pre- and perinatal risk factors for autism spectrum disorder in a New Jersey cohort. $J$ Child Neurol. 2014;29(12):1645-1651.

40. Gardener H, Spiegelman D, Buka SL. Perinatal and neonatal risk factors for autism: a comprehensive meta-analysis. Pediatrics. 2011;128(2): 344-355.

41. Guinchat V, Thorsen P, Laurent C, Cans C, Bodeau N, Cohen D. Pre-, periand neonatal risk factors for autism. Acta Obstet Gynecol Scand. 2012; 91(3):287-300.

42. Froehlich-Santino W, Londono Tobon A, Cleveland S, et al. Prenatal and perinatal risk factors in a twin study of autism spectrum disorders. J Psychiatr Res. 2014;54:100-108.

43. Hultman CM, Sandin S, Levine SZ, Lichtenstein P, Reichenberg A. Advancing paternal age and risk of autism: new evidence from a population-based study and a meta-analysis of epidemiological studies. Mol Psychiatry. 2011;16(12):1203-1212.

44. Reichenberg A, Gross R, Weiser M, et al. Advancing paternal age and autism. Arch Gen Psychiatry. 2006;63(9):1026-1032. 
45. Simonoff E. Genetic counseling in autism and pervasive developmental disorders. J Autism Dev Disord. 1998;28(5):447-456.

46. Abrahams BS, Geschwind DH. Advances in autism genetics: on the threshold of a new neurobiology. Nat Rev Genet. 2008;9(5): 341-355.

47. Freitag CM, Staal W, Klauck SM, Duketis E, Waltes R. Genetics of autistic disorders: review and clinical implications. Eur Child Adolesc Psychiatry. 2010;19(3):169-178.

48. Fombonne E. Epidemiology of autistic disorder and other pervasive developmental disorders. J Clin Psychiatry. 2005;66(suppl 10):3-8.

49. Werling DM, Geschwind DH. Sex differences in autism spectrum disorders. Curr Opin Neurol. 2013;26(2):146-153.

50. Craig MC, Zaman SH, Daly EM, et al. Women with autistic-spectrum disorder: magnetic resonance imaging study of brain anatomy. $\mathrm{Br} \mathrm{J}$ Psychiatry. 2007;191:224-228.

51. Lai MC, Lombardo MV, Suckling J, et al. Biological sex affects the neurobiology of autism. Brain. 2013;136(pt 9):2799-2815.

52. Schaer M, Kochalka J, Padmanabhan A, Supekar K, Menon V. Sex differences in cortical volume and gyrification in autism. Mol Autism. 2015;6:42

53. Tropeano M, Howley D, Gazzellone MJ, et al. Microduplications at the pseudoautosomal SHOX locus in autism spectrum disorders and related neurodevelopmental conditions. J Med Genet. Epub 2016 Apr 12.

54. Wilson C, Murphy CM, McAlonan G, et al. Does sex influence the diagnostic evaluation of autism spectrum disorder in adults? Autism. Epub 2016 Jan 22.

55. Lai MC, Lombardo MV, Auyeung B, Chakrabarti B, Baron-Cohen S. Sex/gender differences and autism: setting the scene for future research J Am Acad Child Adolesc Psychiatry. 2015;54(1):11-24.

56. GOV.UK [webpage on the Internet]. Think Autism. Available from: www.gov.uk/government/publications/think-autism-an-update-to-thegovernment-adult-autism-strategy. Accessed February 11, 2016.

57. D'Astous V, Manthorpe J, Lowton K, Glaser K. Historical social care context of autism: a narrative overview. Br J Soc Work. 2014:1-19.

58. Ecker C, Bookheimer SY, Murphy DG. Neuroimaging in autism spectrum disorder: brain structure and function across the lifespan. Lancet Neurol. 2015;14:1121-1134.

59. Lord CE. Autism: from research to practice. Am Psychol. 2010;65(8): 815-826.

60. Amaral DG, Schumann CM, Nordahl CW. Neuroanatomy of autism. Trends Neurosci. 2008;31(3):137-145.

61. Ashwood KL, Buitelaar J, Murphy D, Spooren W, Charman T. European clinical network: autism spectrum disorder assessments and patient characterisation. Eur Child Adolesc Psychiatry. 2015;24(8):985-995.

62. Lord C, Jones RM. Annual research review: re-thinking the classification of autism spectrum disorders. J Child Psychol Psychiatry. 2012;53(5):490-509.

63. Asperger H. Die "Autistischen Psychopathen" im Kindesalter. Arch Psychiatr Nervenkr. 1943;117:76-136.

64. Frith U. Translation and annotation of "autistic psychopathy" in childhood. In: Asperger H, editor. Autism and Asperger Syndrome. Cambridge: Cambridge University Press; 1991:37-92.

65. American Psychiatric Association. Diagnostic and Statistical Manual of Mental Disorders. 3rd ed. Washington, DC: APA; 1980.

66. American Psychiatric Association. Diagnostic and Statistical Manual of Mental Disorders. 4th ed. Washington, DC: APA; 2000.

67. Young S, Murphy CM, Coghill D. Avoiding the 'twilight zone': recommendations for the transition of services from adolescence to adulthood for young people with ADHD. BMC Psychiatry. 2011;11:174.

68. Huerta M, Bishop SL, Duncan A, Hus V, Lord C. Application of DSM-5 criteria for autism spectrum disorder to three samples of children with DSM-IV diagnoses of pervasive developmental disorders. Am J Psychiatry. 2012;169(10):1056-1064.

69. Wilson CE, Gillan N, Spain D, et al. Comparison of ICD-10R, DSMIV-TR and DSM-5 in an adult autism spectrum disorder diagnostic clinic. J Autism Dev Disord. 2013;43(11):2515-2525.
70. McAlonan GM, Cheung C, Cheung V, Wong N, Suckling J, Chua SE. Differential effects on white-matter systems in high-functioning autism and Asperger's syndrome. Psychol Med. 2009;39(11):1885-1893.

71. McAlonan GM, Suckling J, Wong N, et al. Distinct patterns of grey matter abnormality in high-functioning autism and Asperger's syndrome. J Child Psychol Psychiatry. 2008;49(12):1287-1295.

72. Yu KK, Cheung C, Chua SE, McAlonan GM. Can Asperger syndrome be distinguished from autism? An anatomic likelihood meta-analysis of MRI studies. J Psychiatry Neurosci. 2011;36(6):412-421.

73. World Health Organization. The ICD-10 Classification of Mental and Behavioural Disorders: Diagnostic Criteria for research. Geneva: World Health Organization; 1993.

74. Croen LA, Zerbo O, Qian Y, et al. The health status of adults on the autism spectrum. Autism. 2015;19(7):814-823.

75. Fortuna RJ, Robinson L, Smith TH, et al. Health conditions and functional status in adults with autism: a cross-sectional evaluation. $J$ Gen Intern Med. 2016;31(1):77-84.

76. Tyler CV, Schramm SC, Karafa M, Tang AS, Jain AK. Chronic disease risks in young adults with autism spectrum disorder: forewarned is forearmed. Am J Intellect Dev Disabil. 2011;116(5):371-380.

77. Nicolaidis C, Raymaker D, McDonald K, et al. Comparison of healthcare experiences in autistic and non-autistic adults: a cross-sectional online survey facilitated by an academic-community partnership. $J$ Gen Intern Med. 2013;28(6):761-769.

78. Zerbo O, Massolo ML, Qian Y, Croen LA. A study of physician knowledge and experience with autism in adults in a large integrated healthcare system. J Autism Dev Disord. 2015;45(12):4002-4014.

79. Nicolaidis C, Raymaker DM, Ashkenazy E, et al. "Respect the way I need to communicate with you": healthcare experiences of adults on the autism spectrum. Autism. 2015;19(7):824-831.

80. Cohen S, Conduit R, Lockley SW, Rajaratnam SM, Cornish KM. The relationship between sleep and behavior in autism spectrum disorder (ASD): a review. J Neurodev Disord. 2014;6(1):44.

81. Richdale AL, Schreck KA. Sleep problems in autism spectrum disorders: prevalence, nature, \& possible biopsychosocial aetiologies. Sleep Med Rev. 2009;13(6):403-411.

82. Baker EK, Richdale AL. Sleep patterns in adults with a diagnosis of high-functioning autism spectrum disorder. Sleep. 2015;38(11): $1765-1774$.

83. Tani P, Lindberg N, Nieminen-von Wendt T, et al. Sleep in young adults with Asperger syndrome. Neuropsychobiology. 2004;50(2): $147-152$.

84. Limoges E, Mottron L, Bolduc C, Berthiaume C, Godbout R. Atypical sleep architecture and the autism phenotype. Brain. 2005;128(pt 5): 1049-1061.

85. Malow BA, Byars K, Johnson K, et al; Sleep Committee of the Autism Treatment Network. A practice pathway for the identification, evaluation, and management of insomnia in children and adolescents with autism spectrum disorders. Pediatrics. 2012;130(suppl 2): S106-S124

86. Hollway JA, Aman MG. Pharmacological treatment of sleep disturbance in developmental disabilities: a review of the literature. Res Dev Disabil. 2011;32(3):939-962.

87. Buie T, Campbell DB, Fuchs GJ 3rd, et al. Evaluation, diagnosis, and treatment of gastrointestinal disorders in individuals with ASDs: a consensus report. Pediatrics. 2010;125(supp1 1):S1-S18.

88. McElhanon BO, McCracken C, Karpen S, Sharp WG. Gastrointestinal symptoms in autism spectrum disorder: a meta-analysis. Pediatrics. 2014;133(5):872-883.

89. Furuta GT, Williams K, Kooros K, et al. Management of constipation in children and adolescents with autism spectrum disorders. Pediatrics. 2012;130(suppl 2):S98-S105.

90. Sharp WG, Berry RC, McCracken C, et al. Feeding problems and nutrient intake in children with autism spectrum disorders: a meta-analysis and comprehensive review of the literature. J Autism Dev Disord. 2013;43(9):2159-2173. 
91. Berry RC, Novak P, Withrow N, et al. Nutrition management of gastrointestinal symptoms in children with autism spectrum disorder: guideline from an expert panel. J Acad Nutr Diet. 2015;115(12): 1919-1927.

92. Elder JH, Shankar M, Shuster J, Theriaque D, Burns S, Sherrill L. The gluten-free, casein-free diet in autism: results of a preliminary double blind clinical trial. J Autism Dev Disord. 2006;36(3):413-420.

93. Kirby M, Danner E. Nutritional deficiencies in children on restricted diets. Pediatr Clin North Am. 2009;56(5):1085-1103.

94. El Achkar CM, Spence SJ. Clinical characteristics of children and young adults with co-occurring autism spectrum disorder and epilepsy. Epilepsy Behav. 2015;47:183-190.

95. Reilly C, Atkinson P, Das KB, et al. Features of autism spectrum disorder (ASD) in childhood epilepsy: a population-based study. Epilepsy Behav. 2015;42:86-92.

96. Accardo JA, Malow BA. Sleep, epilepsy, and autism. Epilepsy Behav. 2015;47:202-206.

97. Frye RE. Metabolic and mitochondrial disorders associated with epilepsy in children with autism spectrum disorder. Epilepsy Behav. 2015;47:147-157.

98. Hofvander B, Delorme R, Chaste P, et al. Psychiatric and psychosocial problems in adults with normal-intelligence autism spectrum disorders. BMC Psychiatry. 2009;9:35

99. Lugnegård T, Hallerbäck MU, Gillberg C. Psychiatric comorbidity in young adults with a clinical diagnosis of Asperger syndrome. Res Dev Disabil. 2011;32(5):1910-1917.

100. Russell AJ, Mataix-Cols D, Anson M, Murphy DG. Obsessions and compulsions in Asperger syndrome and high-functioning autism. Br J Psychiatry. 2005;186:525-528.

101. Johnston K, Dittner A, Bramham J, Murphy C, Knight A, Russell A. Attention deficit hyperactivity disorder symptoms in adults with autism spectrum disorders. Autism Res. 2013;6(4):225-236.

102. Simonoff E, Jones CR, Baird G, Pickles A, Happé F, Charman T. The persistence and stability of psychiatric problems in adolescents with autism spectrum disorders. J Child Psychol Psychiatry. 2013;54(2):186-194.

103. Russell A, Murphy CM, Wilson CE, et al. The mental health of individuals referred for assessment of autism spectrum disorder (ASD) in adulthood: a clinic report. Autism. Epub 2015 Oct 15.

104. Hill EL. Executive dysfunction in autism. Trends Cogn Sci. 2004; 8(1):26-32.

105. Luke L, Clare IC, Ring H, Redley M, Watson P. Decision-making difficulties experienced by adults with autism spectrum conditions. Autism. 2012;16(6):612-621.

106. Rommelse NN, Geurts HM, Franke B, Buitelaar JK, Hartman CA. A review on cognitive and brain endophenotypes that may be common in autism spectrum disorder and attention-deficit/hyperactivity disorder and facilitate the search for pleiotropic genes. Neurosci Biobehav Rev. 2011;35(6):1363-1396.

107. Wilson CE, Happe F, Wheelwright SJ, et al; Sauter DA; MRC AIMS Consortium. The neuropsychology of male adults with high-functioning autism or asperger syndrome. Autism Res. 2014;7(5): $568-581$.

108. Green J, Gilchrist A, Burton D, Cox A. Social and psychiatric functioning in adolescents with Asperger syndrome compared with conduct disorder. J Autism Dev Disord. 2000;30(4):279-293.

109. Corbett BA, Constantine LJ, Hendren R, Rocke D, Ozonoff S. Examining executive functioning in children with autism spectrum disorder, attention deficit hyperactivity disorder and typical development. Psychiatry Res. 2009;166(2-3):210-222.

110. Schatz AM, Weimer AK, Trauner DA. Brief report: attention differences in Asperger syndrome. J Autism Dev Disord. 2002;32(4):333-336.

111. Sturm H, Fernell E, Gillberg C. Autism spectrum disorders in children with normal intellectual levels: associated impairments and subgroups. Dev Med Child Neurol. 2004;46(7):444-447.

112. Allen G, Courchesne E. Attention function and dysfunction in autism. Front Biosci. 2001;6:D105-D119.
113. Taurines R, Schwenck C, Westerwald E, Sachse M, Siniatchkin M, Freitag C. ADHD and autism: differential diagnosis or overlapping traits? A selective review. Atten Defic Hyperact Disord. 2012;4(3): 115-139.

114. Santosh PJ, Baird G, Pityaratstian N, Tavare E, Gringras P. Impact of comorbid autism spectrum disorders on stimulant response in children with attention deficit hyperactivity disorder: a retrospective and prospective effectiveness study. Child. 2006;32(5):575-583.

115. Ghanizadeh A. Atomoxetine for treating ADHD symptoms in autism: a systematic review. J Atten Disord. 2013;17(8):635-640.

116. Reiersen AM, Todd RD. Co-occurrence of ADHD and autism spectrum disorders: phenomenology and treatment. Expert Rev Neurother. 2008;8(4):657-669.

117. Research Units on Pediatric Psychopharmacology Autism Network. Randomized, controlled, crossover trial of methylphenidate in pervasive developmental disorders with hyperactivity. Arch Gen Psychiatry. 2005;62(11):1266-1274.

118. Greenhill LL, Swanson JM, Vitiello B, et al. Impairment and deportment responses to different methylphenidate doses in children with ADHD: the MTA titration trial. J Am Acad Child Adolesc Psychiatry. 2001;40(2):180-187.

119. Mahajan R, Bernal MP, Panzer R, et al; Autism Speaks Autism Treatment Network Psychopharmacology Committee. Clinical practice pathways for evaluation and medication choice for attentiondeficit/hyperactivity disorder symptoms in autism spectrum disorders. Pediatrics. 2012;130(Suppl 2):S125-S138.

120. Christakou A, Murphy CM, Chantiluke K, et al. Disorder-specific functional abnormalities during sustained attention in youth with attention deficit hyperactivity disorder (ADHD) and with autism. Mol Psychiatry. 2013;18(2):236-244.

121. Chantiluke K, Christakou A, Murphy CM, et al. Disorder-specific functional abnormalities during temporal discounting in youth with attention deficit hyperactivity disorder (ADHD), Autism and comorbid ADHD and autism. Psychiatry Res. 2014;223(2): 113-120.

122. Bakken TL, Helverschou SB, Eilertsen DE, et al. Psychiatric disorders in adolescents and adults with autism and intellectual disability: a representative study in one county in Norway. Res Dev Disabil. 2010; 31(6):1669-1677.

123. Cadman T, Spain D, Johnston P, et al. Obsessive-compulsive disorder in adults with high-functioning autism spectrum disorder: what does self-report with the OCI-R tell us? Autism Res. 2015;8(5): 477-485.

124. Kohn R, Saxena S, Levav I, Saraceno B. The treatment gap in mental health care. Bull World Health Organ. 2004;82(11):858-866.

125. Russell AJ, Mataix-Cols D, Anson MA, Murphy DG. Psychological treatment for obsessive-compulsive disorder in people with autism spectrum disorders - a pilot study. Psychother Psychosom. 2009; 78(1):59-61.

126. NICE [webpage on the Internet]. National Institute for Health and Care Excellence (NICE) Guidelines for the Care of Adults with ASD. Available from: www.nice.org.uk/guidance/cg142. Accessed February 11, 2016.

127. Lord C, Rutter M, Le Couteur A. Autism diagnostic interview-revised: a revised version of a diagnostic interview for caregivers of individuals with possible pervasive developmental disorders. J Autism Dev Disord. 1994;24(5):659-685.

128. Lord C, Risi S, Lambrecht L, et al. The autism diagnostic observation schedule-generic: a standard measure of social and communication deficits associated with the spectrum of autism. J Autism Dev Disord. 2000;30(3):205-223.

129. Jones RM, Lord C. Diagnosing autism in neurobiological research studies. Behav Brain Res. 2013;251:113-124.

130. Constantino JN, Davis SA, Todd RD, et al. Validation of a brief quantitative measure of autistic traits: comparison of the social responsiveness scale with the autism diagnostic interview-revised. J Autism Dev Disord. 2003;33(4):427-433. 
131. Constantino JN, Todd RD. Intergenerational transmission of subthreshold autistic traits in the general population. Biol Psychiatry. 2005; 57(6):655-660

132. Baron-Cohen S, Wheelwright S, Skinner R, Martin J, Clubley E. The autism-spectrum quotient (AQ): evidence from Asperger syndrome/ high-functioning autism, males and females, scientists and mathematicians. J Autism Dev Disord. 2001;31(1):5-17.

133. Ashwood KL, Gillan N, Horder J, et al. Predicting the diagnosis of autism in adults using the Autism-Spectrum Quotient (AQ) Questionnaire. Psychological Medicine. In Press.

134. Bassett AS, McDonald-McGinn DM, Devriendt K, et al; International 22q11.2 Deletion Syndrome Consortium. Practical guidelines for managing patients with 22q11.2 deletion syndrome. J Pediatr. 2011; 159(2):332e1-339e1.

135. Ecker C, Rocha-Rego V, Johnston P, et al; MRC AIMS Consortium. Investigating the predictive value of whole-brain structural MR scans in autism: a pattern classification approach. Neuroimage. 2010;49(1):44-56.

136. Broadstock M, Doughty C, Eggleston M. Systematic review of the effectiveness of pharmacological treatments for adolescents and adults with autism spectrum disorder. Autism. 2007;11(4):335-348.

137. Esbensen AJ, Greenberg JS, Seltzer MM, Aman MG. A longitudinal investigation of psychotropic and non-psychotropic medication use among adolescents and adults with autism spectrum disorders. J Autism Dev Disord. 2009;39(9):1339-1349.

138. Murray ML, Hsia Y, Glaser K, et al. Pharmacological treatments prescribed to people with autism spectrum disorder (ASD) in primary health care. Psychopharmacology. 2014;231(6):1011-1021.

139. Hsia Y, Wong AY, Murphy DG, Simonoff E, Buitelaar JK, Wong IC. Psychopharmacological prescriptions for people with autism spectrum disorder (ASD): a multinational study. Psychopharmacology. 2014;231(6):999-1009.

140. Wong AY, Hsia Y, Chan EW, et al. The variation of psychopharmacological prescription rates for people with autism spectrum disorder (ASD) in 30 countries. Autism Res. 2014;7(5):543-554.

141. Steckler T, Spooren W, Murphy D. Autism spectrum disorders - an emerging area in psychopharmacology. Psychopharmacology. 2014; 231(6):977-978.

142. Murphy D, Spooren W. EU-AIMS: a boost to autism research. Nat Rev Drug Discov. 2012;11(11):815-816.

143. Bishop-Fitzpatrick L, Minshew NJ, Eack SM. A systematic review of psychosocial interventions for adults with autism spectrum disorders. J Autism Dev Disord. 2013;43(3):687-694

144. Spek AA, van Ham NC, Nyklíček I. Mindfulness-based therapy in adults with an autism spectrum disorder: a randomized controlled trial. Res Dev Disabil. 2013;34(1):246-253.

145. Hesselmark E, Plenty S, Bejerot S. Group cognitive behavioural therapy and group recreational activity for adults with autism spectrum disorders: a preliminary randomized controlled trial. Autism 2013;18(6):672-683.

146. Eack SM, Greenwald DP, Hogarty SS, et al. Cognitive enhancement therapy for adults with autism spectrum disorder: results of an 18-month feasibility study. J Autism Dev Disord. 2013;43(12): 2866-2877.

147. NICE. Guidelines Including Transition Recommendations. Available from: www.nice.org.uk/guidance/cg170/resources/guidance-autism NICE 2012.

148. Cheak-Zamora NC, Yang X, Farmer JE, Clark M. Disparities in transition planning for youth with autism spectrum disorder. Pediatrics 2013;131(3):447-454.

149. Stewart D. Transition to adult services for young people with disabilities: current evidence to guide future research. Dev Med Child Neurol. 2009;51(Suppl 4):169-173.

150. Belling R, McLaren S, Paul M, et al. The effect of organisational resources and eligibility issues on transition from child and adolescent to adult mental health services. J Health Serv Res Policy. 2014;19(3): 169-176.
151. American Academy of Pediatrics; American Academy of Family Physicians; American College of Physicians-American Society of Internal Medicine. A consensus statement on health care transitions for young adults with special health care needs. Pediatrics. 2002;110 (6 pt 2):1304-1306.

152. Taylor JL, Henninger NA. Frequency and correlates of service access among youth with autism transitioning to adulthood. J Autism Dev Disord. 2015;45(1):179-191.

153. Happé F, Charlton RA. Aging in autism spectrum disorders: a minireview. Gerontology. 2012;58(1):70-78.

154. Starkstein S, Gellar S, Parlier M, Payne L, Piven J. High rates of parkinsonism in adults with autism. J Neurodev Disord. 2015; 7(1):29.

155. Coppus A, Evenhuis H, Verberne GJ, van Gool P, Eikelenboom P, van Duijin C. Dementia and mortality in persons with Down's syndrome. J Intellect Disabil Res. 2006;50(Pt 10):768-777.

156. Booij J, van Amelsvoort T, Boot E. Co-occurrence of early-onset Parkinson disease and 22q11.2 deletion syndrome: potential role for dopamine transporter imaging. Am J Med Genet A. 2010;152A(11): 2937-2938.

157. Butcher NJ, Kiehl TR, Hazrati LN, et al. Association between earlyonset Parkinson disease and 22q11.2 deletion syndrome: identification of a novel genetic form of Parkinson disease and its clinical implications. JAMA Neurol. 2013;70(11):1359-1366.

158. Lainhart JE. Brain imaging research in autism spectrum disorders: in search of neuropathology and health across the lifespan. Curr Opin Psychiatry. 2015;28(2):76-82.

159. Carper RA, Moses P, Tigue ZD, Courchesne E. Cerebral lobes in autism: early hyperplasia and abnormal age effects. Neuroimage. 2002;16(4):1038-1051.

160. Hazlett HC, Poe MD, Gerig G, et al. Early brain overgrowth in autism associated with an increase in cortical surface area before age 2 years. Arch Gen Psychiatry. 2011;68(5):467-476.

161. Schumann CM, Bloss CS, Barnes CC, et al. Longitudinal magnetic resonance imaging study of cortical development through early childhood in autism. $J$ Neurosci. 2010;30(12):4419-4427.

162. Hardan AY, Libove RA, Keshavan MS, Melhem NM, Minshew NJ. A preliminary longitudinal magnetic resonance imaging study of brain volume and cortical thickness in autism. Biol Psychiatry. 2009;66(4):320-326.

163. Murphy CM, Deeley Q, Daly EM, et al. Anatomy and aging of the amygdala and hippocampus in autism spectrum disorder: an in vivo magnetic resonance imaging study of Asperger syndrome. Autism Res. 2012;5(1):3-12.

164. Langen M, Schnack HG, Nederveen H, et al. Changes in the developmental trajectories of striatum in autism. Biol Psychiatry. 2009;66(4):327-333.

165. Ecker C, Shahidiani A, Feng Y, et al. The effect of age, diagnosis, and their interaction on vertex-based measures of cortical thickness and surface area in autism spectrum disorder. JNeural Transm. 2014; 121(9):1157-1170.

166. Wallace GL, Dankner N, Kenworthy L, Giedd JN, Martin A. Agerelated temporal and parietal cortical thinning in autism spectrum disorders. Brain. 2010;133(Pt 12):3745-3754.

167. Fidler DJ, Bailey JN, Smalley SL. Macrocephaly in autism and other pervasive developmental disorders. Dev Med Child Neurol. 2000; 42(11):737-740.

168. Raznahan A, Wallace GL, Antezana L, et al. Compared to what? Early brain overgrowth in autism and the perils of population norms. Biol Psychiatry. 2013;74(8):563-575.

169. Campbell DJ, Chang J, Chawarska K. Early generalized overgrowth in autism spectrum disorder: prevalence rates, gender effects, and clinical outcomes. J Am Acad Child Adolesc Psychiatry. 2014;53(10): 1063e5-1073e5.

170. Murphy CM, Christakou A, Daly EM, et al. Abnormal functional activation and maturation of fronto-striato-temporal and cerebellar regions during sustained attention in autism spectrum disorder. Am J Psychiatry. 2014;171(10):1107-1116. 
171. Mendez MA, Horder J, Myers J, et al. The brain GABA-benzodiazepine receptor alpha-5 subtype in autism spectrum disorder: a pilot [(11)C] Ro15-4513 positron emission tomography study. Neuropharmacology. 2013;68:195-201.

172. Daly E, Ecker C, Hallahan B, et al. Response inhibition and serotonin in autism: a functional MRI study using acute tryptophan depletion. Brain. 2014;137(Pt 9):2600-2610.

173. Daly EM, Deeley Q, Ecker C, et al. Serotonin and the neural processing of facial emotions in adults with autism: an fMRI study using acute tryptophan depletion. Arch Gen Psychiatry. 2012;69(10):1003-1013.

174. Nakamura K, Sekine Y, Ouchi Y, et al. Brain serotonin and dopamine transporter bindings in adults with high-functioning autism. Arch Gen Psychiatry. 2010;67(1):59-68.

175. Guastella AJ, Hickie IB. Oxytocin treatment, circuitry and autism: a critical review of the literature placing oxytocin into the autism context. Biol Psychiatry. 2016;79(3):234-242.
176. Anagnostou E, Soorya L, Chaplin W, et al. Intranasal oxytocin versus placebo in the treatment of adults with autism spectrum disorders: a randomized controlled trial. Mol Autism. 2012;3(1):16.

177. Anagnostou E, Soorya L, Brian J, et al. Intranasal oxytocin in the treatment of autism spectrum disorders: a review of literature and early safety and efficacy data in youth. Brain Res. 2014;1580:188-198.

178. ICD-10. World Health Organization. International Classification of Diseases: Diagnostic Criteria for Research. 10th ed. Geneva: World Health Organization; 1992.

179. American Psychiatric Association. Diagnostic and Statistical Manual of Mental Disorders. 5th ed. Arlington, VA: American Psychiatric Association; 2013.

\section{Publish your work in this journal}

Neuropsychiatric Disease and Treatment is an international, peerreviewed journal of clinical therapeutics and pharmacology focusing on concise rapid reporting of clinical or pre-clinical studies on a range of neuropsychiatric and neurological disorders. This journal is indexed on PubMed Central, the 'PsycINFO' database and CAS, and is the official journal of The International Neuropsychiatric Association (INA). The manuscript management system is completely online and includes a very quick and fair peer-review system, which is all easy to use. Visit http://www.dovepress.com/testimonials.php to read real quotes from published authors.

Submit your manuscript here: http://www.dovepress.com/neuropsychiatric-disease-and-treatment-journal 